\title{
Environment Problem Identified
}

National Cancer Institute

\section{Source}

National Cancer Institute. Environment Problem Identified. NCI Thesaurus. Code C92051.

Problems that occurred due to factors within the environment e.g. dust, dirt, humidity, temperature. 